\title{
Progress on Matrix SiC Processing and Properties for Fully Ceramic Microencapsulated Fuel Form
}

\author{
K.A. Terrani ${ }^{1}$, J.O. Kiggans, C.M. Silva, C. Shih, Y. Katoh, L.L. Snead \\ Oak Ridge National Laboratory, Oak Ridge, TN 37831, USA
}

\begin{abstract}
The consolidation mechanism and resulting properties of the silicon carbide ( $\mathrm{SiC}$ ) matrix of fully ceramic microencapsulated (FCM) fuel form are discussed. The matrix is produced via the nano-infiltration transient eutectic-forming (NITE) process. Coefficient of thermal expansion, thermal conductivity, and strength characteristics of this $\mathrm{SiC}$ matrix have been characterized in the unirradiated state. An ad hoc methodology for estimation of thermal conductivity of the neutron-irradiated NITE-SiC matrix is also provided to aid fuel performance modeling efforts specific to this concept. Finally, specific processing methods developed for production of an optimal and reliable fuel form using this process are summarized. These various sections collectively report the progress made to date on production of optimal FCM fuel form to enable its application in light water and advanced reactors.
\end{abstract}

\section{Introduction}

Fully ceramic microencapsulated (FCM) fuels consist of coated fuel particles embedded inside a neutron radiation tolerant silicon carbide $(\mathrm{SiC})$ matrix $[1,2]$. Envisioned applications for this fuel form spans a number of thermal reactors including light water [3-7] and salt-cooled reactors [8]. The method deemed most appropriate and used to date for consolidation of this matrix adheres to the nano-infiltration transient eutectic-forming (NITE) SiC fabrication strategy [9-11]. The NITE technique is a special manifestation of liquid-phase sintering of $\mathrm{SiC}$ that utilizes $\mathrm{SiC}$ nanopowder feedstock and requires addition of less oxide additives (at a given processing temperature) than with the traditional liquid-phase sintering technique to yield a dense material after high-temperature processing [11]. The maximum temperature $\left(\sim 1900^{\circ} \mathrm{C}\right)$ and applied pressure $(\sim 10 \mathrm{MPa})$ required for consolidation to reach a high-density material remains below the limit of significant creep and grain growth in $\mathrm{SiC}$ materials [12, 13], enabling incorporation of SiC fibers or SiC-coated fuel particles inside the NITE-SiC matrix without significant degradation and loss of integrity in these constituents. Limiting the extent of the oxide secondary phase content via the NITE process promotes a radiation-stable matrix [14] along with superior thermal conductivity as compared to conventional urania fuel pellets $[2,15]$. Also, NITE processing simplifies $\mathrm{SiC}$ matrix consolidation when compared to the other radiation-stable variant, chemical vapor deposited (CVD)-SiC, and offers a significantly more uniform and dense matrix free of large pores.

${ }^{1}$ Corresponding author: terranika@ornl.gov, 865-576-0264

The United States Government retains, and by accepting the article for publication, the publisher acknowledges that the United States Government retains, a non-exclusive, paid-up, irrevocable, worldwide license to publish or reproduce the published form of this work, or allow others to do so, for United States Government purposes. 
This manuscript reports the results of recent development activities around NITE-SiC processing and properties pertinent to the $\mathrm{SiC}$ matrix of the FCM fuel form. Initially, basic insights into processing mechanism and environmental/constituent effects are discussed. Following that, thermomechanical properties of these materials are reported. Finally, specific processing methodologies developed for optimum FCM fuel form consolidation are discussed.

\section{Experimental Details}

\subsection{Feedstock preparation}

Two different high-purity ( $>99 \%$ ) starting SiC powders were used, one with an average grain size on the order of $80 \mathrm{~nm}$ (Nanomakers, France, Lot\# 12-SiC-122), and the other with an average grain size on the order of $400 \mathrm{~nm}$ (H.C. Starck, Germany, Lot\# AB147381). A lower purity grade of SiC (97\%) nanopowder (40 nm average particle size) was also used for a small portion of the studies (Nanostructured \& Amorphous Materials, Inc., China, Lot\# 4620-123109). The dominant structure of the SiC in all the powders was the cubic allotrope ( $\mathrm{F} 4 \overline{3} \mathrm{~m}$ space group). The following oxide additives were also used during the fabrication process: yttria (Nanostructured \& Amorphous Materials Inc., Lot\# 5610-091410), alumina (Nano Products Corp., Lot\# 20100905), and gadolinia (Alfa-Aesar, Lot\# G23N042). SiC powder and oxide additives were mixed and milled using $\mathrm{Si}_{3} \mathrm{~N}_{4}$ or yttria-stabilized zirconia (YSZ) milling media inside an ethanol medium for $24 \mathrm{~h}$. It was later determined that YSZ milling media deposited chips into the feedstock and their use was discontinued. As the total mass fraction of oxide additives was varied during this study, the alumina and yttria were added at a constant ratio of 3.9:2.1 $\mathrm{Al}_{2} \mathrm{O}_{3}: \mathrm{Y}_{2} \mathrm{O}_{3}$ mass ratio. Polyethyleneimine (PEI) dispersant was occasionally added to mixture to enhance dispersion efficiency during milling [11].

\subsection{Matrix Consolidation}

Prior to high-temperature consolidation, the powder feedstock was cold pressed inside a steel die. Monolithic green bodies prepared from various $\mathrm{SiC}$ nanopowders via biaxial cold pressing at $14 \mathrm{MPa}$ exhibited green density in the range of 30 to $45 \%$ of theoretical $\mathrm{SiC}$ density with higher green body density associated with the larger diameter powder. Higher applied compaction pressures (up to $70 \mathrm{MPa}$ ) resulted in an increase of less than 3\% in green density. Cold isostatic pressing (CIP) of samples at 40 $\mathrm{MPa}$ following initial biaxial cold pressing also did not improve the compact density within measurable accuracy $(\sim 1 \%)$. Green compacts prepared at constant pressure by biaxial cold pressing mixtures of powders with different average diameters exhibited a density that varied linearly with powder composition between the values belonging to each pure powder. Pressureless sintering and hot-pressing were both carried out in graphite furnaces with stagnant $\mathrm{N}_{2}$ or Ar atmospheres at slightly below 1 atm. The density of the material after consolidation was determined using the Archimedes' method.

\subsection{Fuel Form Production}

Surrogate TRISO fuel particles with a YSZ kernel, instead of uranium bearing oxides and carbides, were used during this development process [16]. Nicalon ${ }^{\mathrm{TM}} \mathrm{SiC}$ fiber bundles (0.4-mm-thick layers with a $55^{\circ}$ braid angle) braided into open-ended tubes (Textile Engineering and Manufacturing Inc., Woonsocket, 
RI) were used during FCM fuel form production to contain the particles to the inner surface of the pellet (Sect. 5.2). Pellet centerless grinding was carried out using a PP-8000 Precision Grinding Unit (Tru-Tech Systems, Mt. Clemens, MI).

\subsection{Analytical and test techniques}

Thermogravimetry analysis (TGA) was performed using a Netzsch Simultaneous Thermal Analyzer (STA) model 449 F1. Green compacts were placed inside a tungsten sample holder and examined inside the TGA with a flowing Ar atmosphere. Linear thermal expansion was measured using a push-rod dilatometer (Netzsch DIL $402 \mathrm{CD}$ ) at a constant heating rate equal to or slower than $5{ }^{\circ} \mathrm{C} / \mathrm{min}$, operated per ASTM E228-06, although specimen geometry deviated from the strict requirements of the standard. Thermal diffusivity measurements were carried out using a Netzsch LFA 457 laser flash instrument per ASTM E1461-11. Monotonic equibiaxial testing was carried out in conformance to ASTM C1499-05 on $6 \times 6 \times 0.5-\mathrm{mm}$ monolithic specimens.

X-ray radiography for single particles was performed using a MicroXCTTM (Xradia, Inc.) system operating at a tube voltage of $40 \mathrm{kV}$ and consisting of a microfocus X-ray source with a tungsten target and a Peltier Cooled CCD detector system equipped with a scintillator. Full pellet X-ray radiography was performed using a Seifert unit with a $1.5-\mathrm{mm}$ focal spot, a 36-in. source to film distance operating at 45 $\mathrm{kV}$, and 2-mA. 48-s exposures on a Kodak HR image plate produced the final images. Scanning electron microscopy (SEM) studies were conducted with a JEOL 6500 FEG-type microscope operating at an accelerating potential of $15 \mathrm{kV}$.

\section{Processing Mechanism and Environmental/Constituent Effects}

\subsection{Thermogravimetry analysis}

Thermogravimetry analysis of green compacts of unmixed $\mathrm{SiC}$ nanopowder and mixed NITE feedstock was carried out to gain insights with regards to material evolution during the processing. The specimens were cylindrical green compacts, roughly $5 \mathrm{~mm}$ in diameter and height. Fig. 1 shows the actual and differential (with respect to time) mass change in green samples undergoing a temperature ramp-up of 20 ${ }^{\circ} \mathrm{C} / \mathrm{min}$ from room temperature to $1810^{\circ} \mathrm{C}$, followed by a hold at this maximum temperature for $1 \mathrm{~h}$. As shown in Fig. 1(a), both of the specimens experience mass loss, with the NITE feedstock losing an additional $7 \%$ loss. This is very close to the sum of mass fractions of the oxide additives and PEI ( $6 \mathrm{wt} \%$ $\mathrm{Al}_{2} \mathrm{O}_{3}+\mathrm{Y}_{2} \mathrm{O}_{3}$ and $1 \mathrm{wt} \% \mathrm{PEI}$ ). Given the large surface-to-volume ratio for these small green bodies, excessive mass volatilization is expected. 

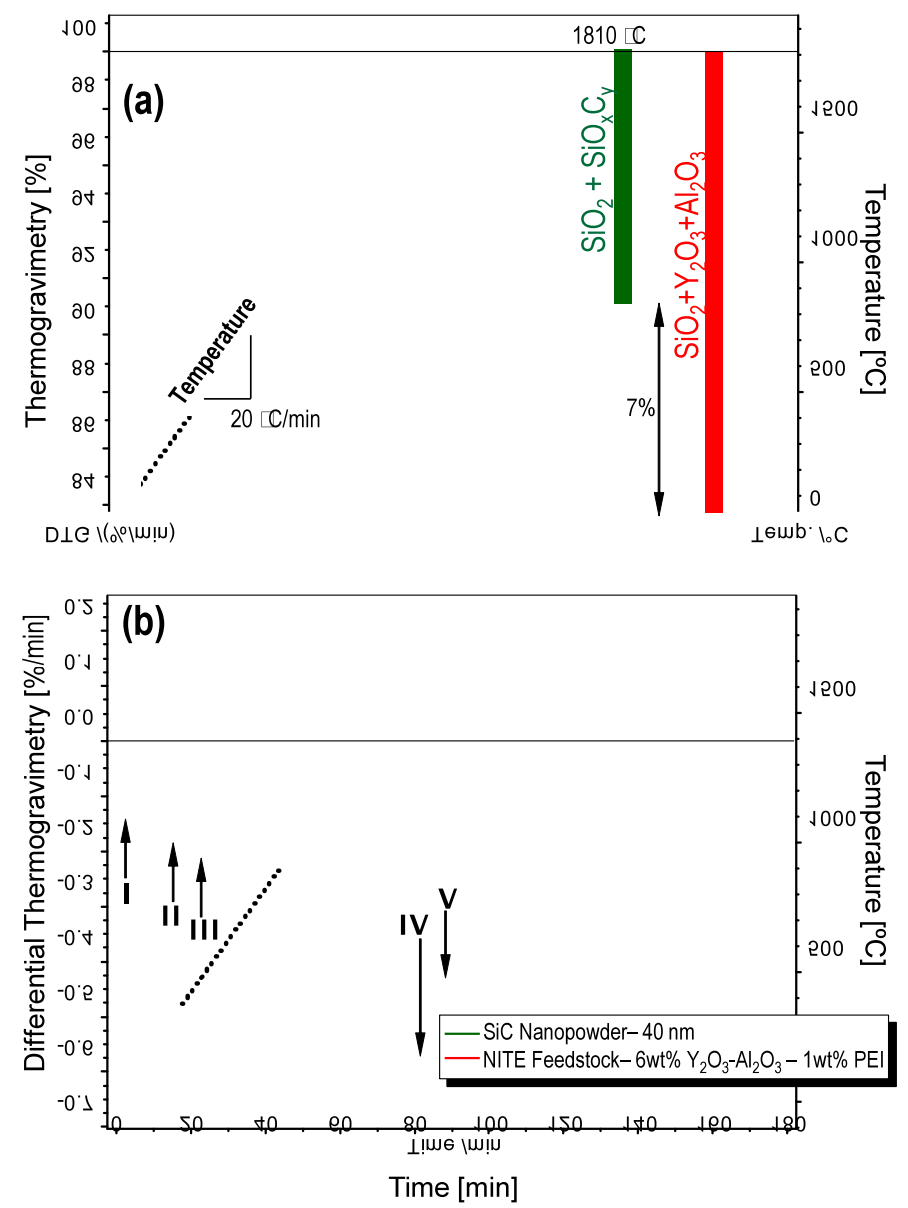

Fig. 1. Thermogravimetry on green pellets of SiC nanopowder and milled NITE feedstock in a flowing Ar atmosphere.

The various peaks in mass loss rate are labeled in Fig. 1(b). Peak I at $80{ }^{\circ} \mathrm{C}$ is observed for both the $\mathrm{SiC}$ nanopowder and NITE feedstock; it corresponds to evaporation of residual water. Peak II, occurring at $350{ }^{\circ} \mathrm{C}$, corresponds to PEI decomposition. Note that a separate TGA test on pure PEI was carried out under similar atmosphere with a ramp-rate of $10{ }^{\circ} \mathrm{C} / \mathrm{min}$, and full decomposition was complete at $425{ }^{\circ} \mathrm{C}$ (max mass loss rate at $380{ }^{\circ} \mathrm{C}$ ). The origin of peak III at $480{ }^{\circ} \mathrm{C}$ is unclear but it is likely due to the presence of PEI or another impurity introduced during the milling stage. Note that peaks II and III are absent for the SiC nanopowder where no PEI was added and no milling operation was carried out.

At higher temperatures $\left(>1400{ }^{\circ} \mathrm{C}\right)$ the $\mathrm{SiC}$ nanopowder loses mass, likely due to loss of oxide and oxycarbide species that are present on the surface of the nanopowder [11, 17]. This process peaks (Peak IV) at $\sim 1625^{\circ} \mathrm{C}$ and largely subsides below $1800{ }^{\circ} \mathrm{C}$ for the $\mathrm{SiC}$ nanopowder. For the NITE feedstock, the onset of high-temperature mass loss occurs earlier and continues well throughout the entire temperature ramp. In addition to Peak IV, a second peak at $1780{ }^{\circ} \mathrm{C}$, labeled as Peak V, appears to be present for the NITE feedstock. The difference in high-temperature mass loss between the $\mathrm{SiC}$ nanopowder and the NITE feedstock is attributed to the presence of the oxide additives in the latter that are susceptible to volatilization. 


\subsection{Pressureless sintering}

To understand optimized sintering conditions and composition, bulk density measurements were carried out on a number of pressureless sintered trials on NITE-SiC specimens prepared from 40-nm-diameter powder (Fig. 2). While $1875^{\circ} \mathrm{C}$ sintering in Ar atmosphere resulted in high-density products, Fig. 2(a) shows that the $\mathrm{N}_{2}$ atmosphere had an adverse effect on densification, especially with low oxide additive contents in the feedstock. Reaction of $\mathrm{N}_{2}$ with $\mathrm{SiC}$ is unlikely since equilibrium partial pressure of $\mathrm{N}_{2}$ over $\mathrm{Si}_{3} \mathrm{~N} 4$ is above $1 \mathrm{~atm}$ at $1875^{\circ} \mathrm{C}$ [18]. Whether nitrogen interacts with the oxide additives is another possibility that needs to be considered. For instance, at these processing temperatures in a $\sim 1 \mathrm{~atm} \mathrm{~N}_{2}$ environment with low oxygen potentials $\left(\log \mathrm{p}_{\mathrm{O} 2}[\mathrm{~atm}]<-16\right)$, formation of $\mathrm{Si}_{2} \mathrm{ON}_{2}$ [18] and $\mathrm{AlON}$ [19] along with more complex quaternary interactions $[20]$ is possible.

Under Ar atmosphere, only a small increase in density was observed as the oxide additive content increased; that is explained by the larger density of the additives themselves. Silica addition resulted in lower densities. Fig. 2(b) shows the extent of weight loss from these specimens that proves consistent with what was observed in Fig. 1(a), on the order of 15\%. The weight-loss fraction increased with increasing oxide additive content. The $2 \%$ increase in weight-loss fraction from the samples without silica compared with the ones containing $2 \%$ silica indicates that the majority of silica is volatilized during the sintering process under the Ar atmosphere. For comparison, Sigl [21] reported higher densities (3.24-3.34

$\mathrm{g} / \mathrm{cm}^{3}$ ) for sintered and subsequently hot isostatically pressed liquid-phase-sintered (LPS) mixtures of SiC specimens with 3-10 $\mathrm{wt} \%$ YAG (yttrium-aluminum garnet) processed at $1970^{\circ} \mathrm{C}$ while reporting mass loss at below $1 \mathrm{wt} \%$. The higher weight loss here could be explained by the larger surface area of the nanopowder and the smaller sample size, with pellet diameter and height on the order of $1 \mathrm{~cm}$. 


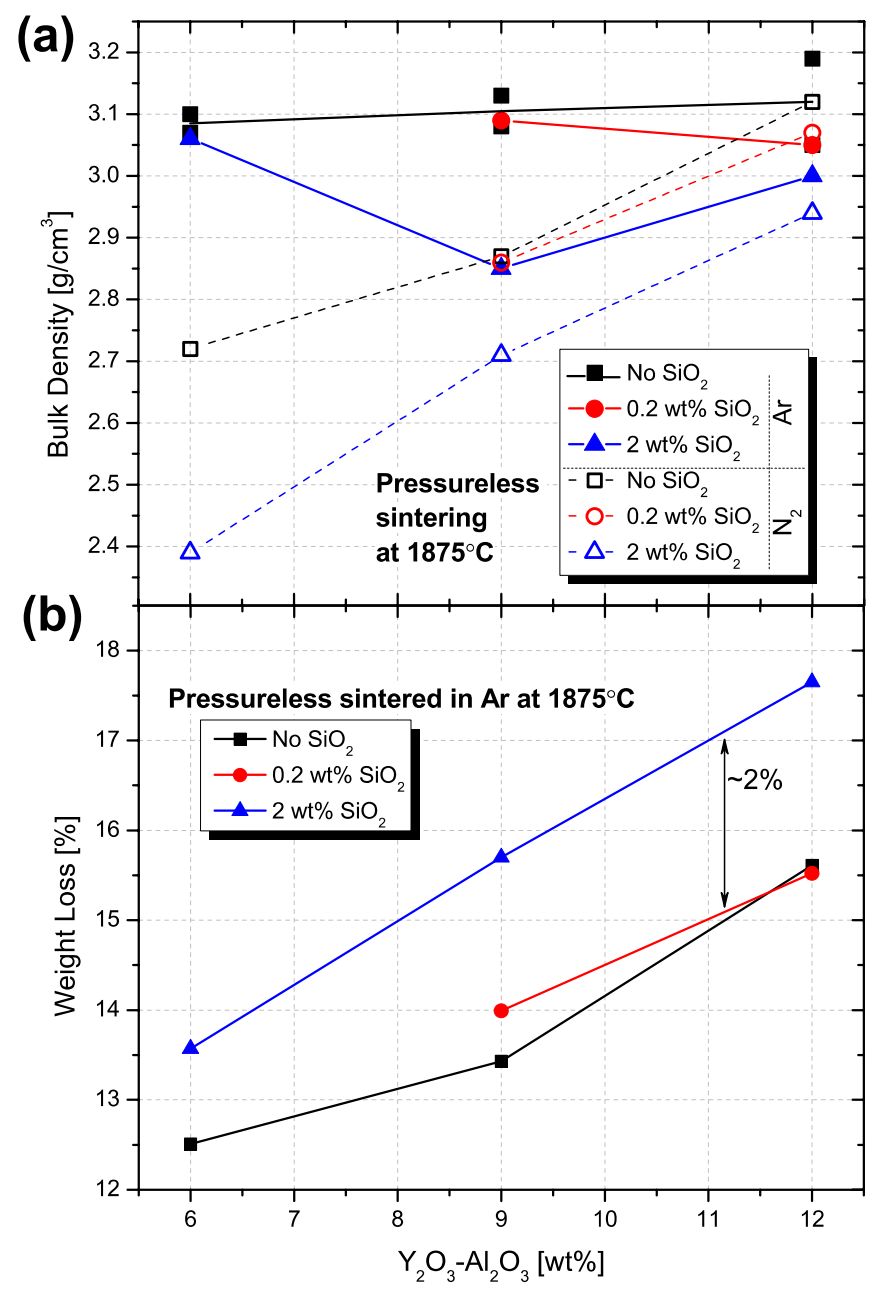

Fig. 2. Bulk density and weight loss measurements on NITE-SiC specimens after pressureless sintering at $1875^{\circ} \mathrm{C}$.

\subsection{Hot-pressing}

Hot-pressing has been used as the de facto technique for production of FCM fuel form [11, 15]. Figure 3 compares the measured density in consolidated NITE SiC specimens, prepared from $80 \mathrm{~nm}$ powder feedstock, and produced via pressureless sintering and hot-pressing. Open symbols show results for samples prepared from an equal mixture of $80 \mathrm{~nm}$ and $400 \mathrm{~nm}$ powders. While pressureless sintering results are consistent with Fig. 2(a), hot-pressing is shown to improve the density of the final material, especially at lower oxide additive contents. Feedstock prepared from the mixture of large and small diameter powders did not result in improved density of the final material with either processing route. 


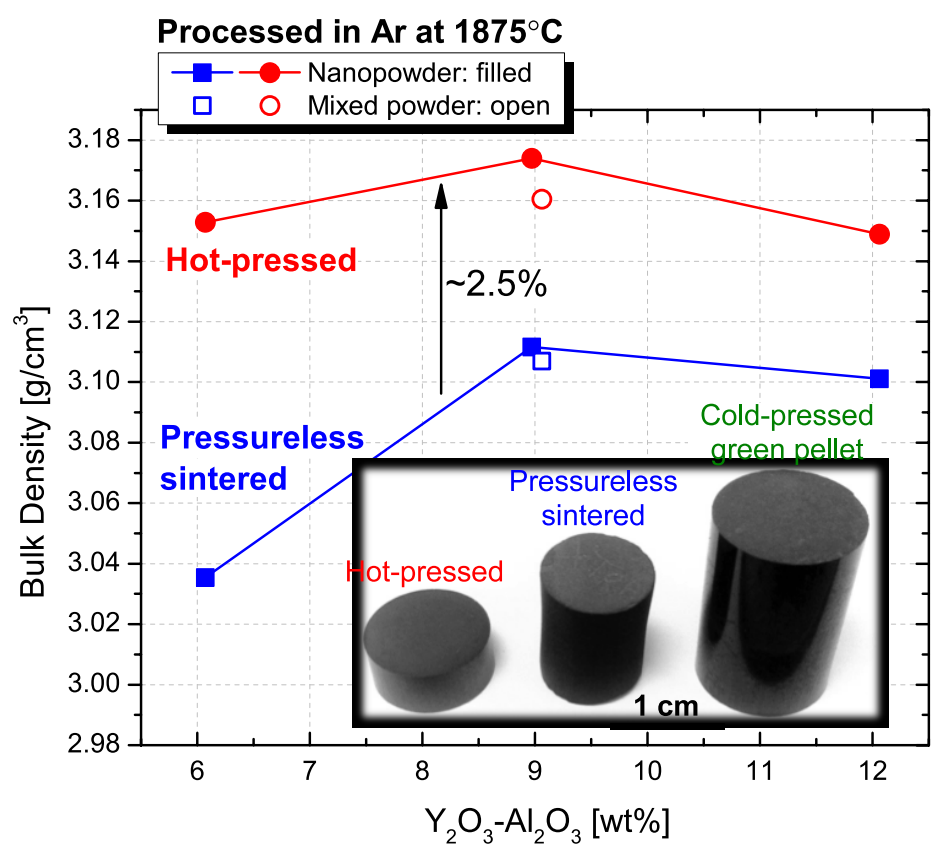

Fig. 3. Comparison of NITE SiC bulk density fabricated via pressureless sintering and hot-pressing. Also shown in the figure is a side-by-side comparison of the cold-pressed, pressureless sintered, and hot-pressed pellets.

Although the difference in the bulk density of the consolidated materials fabricated via pressureless sintering and hot-pressing is relatively small, the microstructure of the materials is quite different. Fig. 4(a) shows the non-uniform oxide distribution in the outer region of the pressureless sintered pellet while Fig. 4(b) shows a large amount of porosity present at this pellet's core. The microstructure of the hotpressed pellet, Fig. 4(c), is uniform in comparison; it contains less porosity; and the oxide distribution is homogenous.



Fig. 4. Backscattered electron image of microstructure in (a) the outer region and (b) the inner core of the pressureless sintered pellet. Image (c) is the hot-pressed pellet. All nanopowder feedstock with $6 \mathrm{wt} \%$ oxide additives. 


\section{Matrix properties}

The basic thermomechanical properties of NITE SiC that constitute the matrix of FCM fuel that are important inputs into fuel performance analysis tools [22] are reported in this section. The results presented in the following subsections are for the hot-pressed materials.

\subsection{Coefficient of thermal expansion}

The coefficients of thermal expansion (CTEs) for two variants of NITE-SiC, hot-pressed at $1875^{\circ} \mathrm{C}$ and high-purity CVD-SiC, were measured and are shown in Fig. 5. Instantaneous CTE $(\alpha)$ was determined from the measured linear expansion using

$$
\alpha=\frac{d}{d T} \ln (I)
$$

where $T$ and $l$ are the test temperature and specimen length, respectively. As shown in Fig. 5, no major discrepancy exists between the two variants of NITE-SiC. The determined CTE for CVD-SiC is slightly lower than the CTE that is reported in prior literature [23, 24]; the lower than expected CTE is likely due to the specimen geometry during these measurements. However, in this side-by-side examination, the CTE for CVD-SiC is consistently higher than the determined CTE for NITE-SiC specimens. This implies that the presence of the small volume fraction of oxide additives $(<5 \%)$ in conjunction with $\mathrm{SiC}$ grains in NITE-SiC results in a smaller CTE than in the pure material. However, alumina [25], YAG [26], or other mixed oxides in this system [27] all exhibit a larger CTE than SiC. Therefore, the nature of this reduction in CTE is unclear at the moment. The overall polynomial fit to the NITE-SiC instantaneous CTE data in the temperature range of 373 to $1273 \mathrm{~K}$ is reported as:

$$
\alpha\left[10^{-6} / \mathrm{K}\right]=0.7738+7.080 \times 10^{-3} T-4.951 \times 10^{-6} T^{2}+1.372 \times 10^{-9} T^{3}
$$



Fig. 5. Instantaneous coefficient of thermal expansion for CVD-SiC [23] and NITE-SiC. 
No changes after irradiation have been observed in the CTEs of high-purity SiC and near-stoichiometric $\mathrm{SiC}$ composites (essentially chemical vapor infiltrated [CVI] $\mathrm{SiC} / \mathrm{SiC}$ ) [24, 28]. Whether this trend extends to be applicable for NITE-SiC variants is not known and requires investigation.

\subsection{Thermal conductivity}

Since the NITE-SiC matrix of the FCM fuel form hosts TRISO fuel particles that produce fission heat, the thermal conductivity of the material is an important parameter. Figure 6 shows the temperature variation of reciprocal thermal diffusivity, measured during both temperature ramp-up and ramp-down, for the hotpressed NITE-SiC specimens discussed in Sect. 3.3. As expected, an approximately linear trend is apparent. The line slope and intercepts from the fits to the data are also reported in Fig. 6.

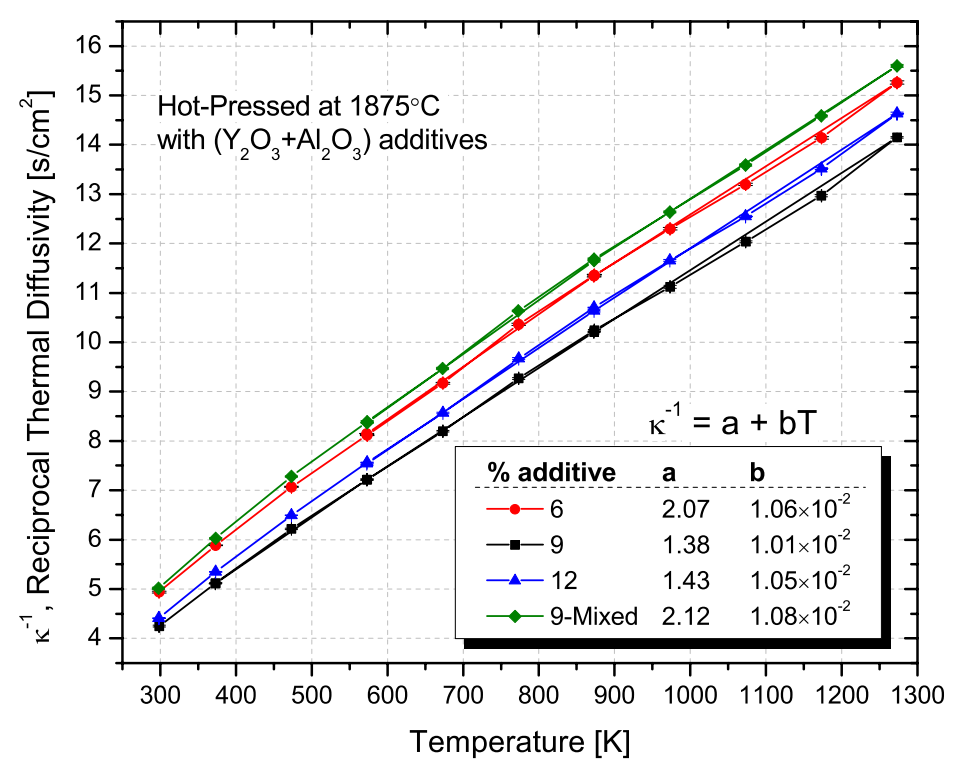

Fig. 6. Reciprocal thermal diffusivity for hot-pressed NITE-SiC as a function of temperature.

Thermal conductivity $(k)$ is defined as

$$
k=\kappa \rho C_{p}
$$

where $\kappa, \rho$, and $C_{p}$, are the thermal diffusivity, density, and heat capacity, respectively. Using the density values in Fig. 3, along with the heat capacity correlation for CVD-SiC from literature [23] (a good estimate for NITE-SiC given the small mass fraction of oxide additives), one can determine the thermal conductivity using Eq. (3). Fig. 7 shows the variation in thermal conductivity for these hot-pressed and sintered NITE-SiC specimens. As shown in Fig. 7, NITE-SiC exhibits high thermal conductivity in the unirradiated state and, depending on the processing conditions and the resulting microstructure (i.e. grain size [29] and oxide distribution), larger and smaller thermal conductivities have been observed in the past. These thermal conductivity values are shown in Fig. 7 for the hot-pressed NITE-SiC variants studied in ref. [15]. Sigl reported similar values for $1970^{\circ} \mathrm{C}$ sintered LPS SiC [21]. For comparison, thermal conductivity of unirradiated urania in the same temperature range varies from $6.5-2.5 \mathrm{~W} / \mathrm{m}-\mathrm{K}$ (essentially 
an order of magnitude lower) [30]. Only a small variation in the magnitude of thermal conductivity among the various NITE-SiC specimens examined in this study is observed. The pressureless sintered specimens exhibited thermal conductivities similar to and in some cases slightly higher than the hotpressed specimens. No significant trend between the magnitude of thermal conductivity and the amount of oxide additives in the NITE-SiC matrix was detected for hot-pressed or pressureless sintered specimens.

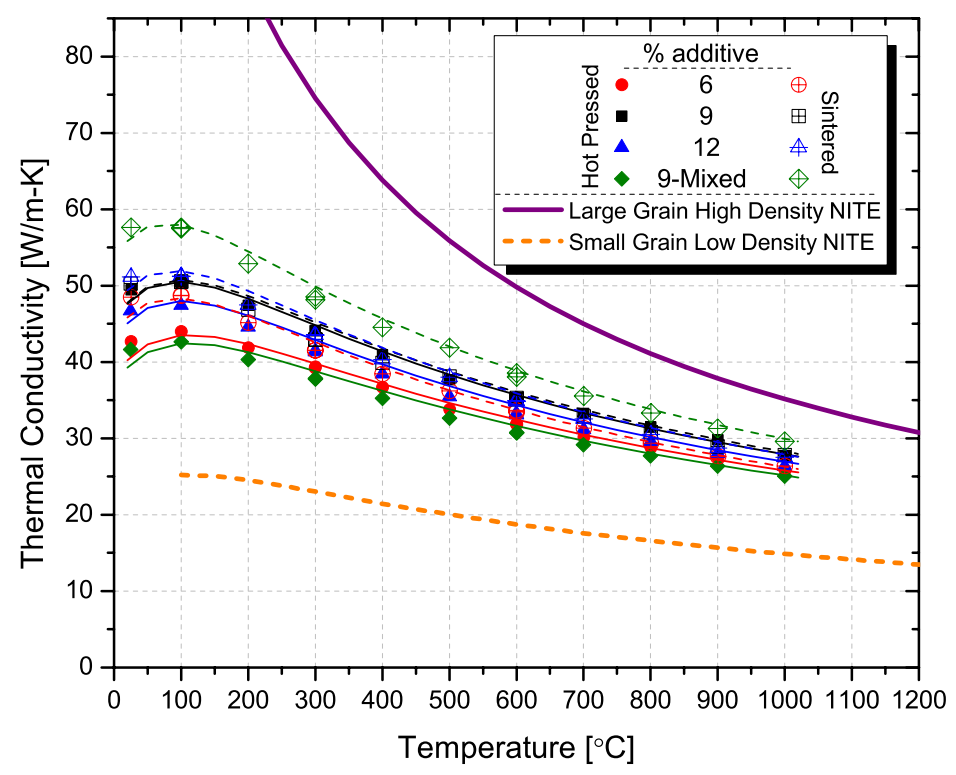

Figure 7. Temperature dependent thermal conductivity of hot-pressed NITE-SiC examined in this study and in ref. [15].

For the fuel matrix application degradation in thermal conductivity as a result of irradiation needs to be considered. Under neutron irradiation thermal conductivity of $\mathrm{SiC}$ degrades significantly to eventually saturate at a temperature-dependent value. This is well-known for CVD-SiC materials [23, 24] and has also been experimentally determined for hot-pressed NITE-SiC pellets irradiated at ORNL's High Flux Isotope Reactor [15]. For ceramic materials, the thermal conductivity can be estimated as the inverse of the linear sum of thermal resistivities from various contributors in the material as follows:

$$
\frac{1}{k}=R_{m}+R_{g b}+R_{U}+R_{d}
$$

where $R$ stands for thermal resistivity, and subscripts $m, g b, U$, and $d$ designate matrix, grain boundary, Umklapp (phonon-phonon), and irradiation defect, respectively. The matrix resistivity term takes into account the effect of all the defects present in the material (be it point defects, impurities, secondary phase, etc.) in the unirradiated state; it itself can be separated to individual terms for each defect that scatters phonons. The temperature-dependent magnitude of the sum of the first three terms can be determined by measuring the thermal conductivity of the unirradiated material as was done in Fig. 7. For the last term in Eq. (4), the magnitude of resistivity due to irradiation defects depends on the type and density of defects in the lattice that form as a result of irradiation. Thermal resistivity of irradiation 
defects as a function of irradiation dose and temperature has been reported for high-purity CVD-SiC [23, 31] and nuclear-grade $\mathrm{SiC} / \mathrm{SiC}$ composites [24]. Only limited data are available for thermal resistivity of irradiation defects in NITE-SiC [15], and an ad hoc estimate is used here to predict the thermal conductivity of NITE-SiC under neutron irradiation as a function of temperature and dose. Although the overall methodology is appropriate, additional experimental data points can provide better coefficients in this formulation and such efforts are under way. The ad hoc estimation here is provided to support fuel performance modeling efforts currently under way [7].

The formulation simply uses Eq. (4) with an irradiation defect thermal resistivity at twice the value for CVD-SiC reported in ref. [23]. Note that this thermal resistivity is comparable to what is observed in CVI $\mathrm{SiC} / \mathrm{SiC}$ composites [24]. Figure 8 provides a comparison between this ad hoc estimation and the limited experimental data available from the high- and low-density NITE-SiC specimens in ref. [15]. The unirradiated thermal conductivity of the samples in Fig. 7 was used along with the irradiation defect thermal resistivity estimate to produce this figure. Note that while this ad hoc method reproduces the experimental observation for the low-density NITE specimen in Fig. 8(b) reasonably, it underestimates the irradiated thermal conductivity for the high-density sample, Fig. 8(a). Therefore, this method is deemed conservative and appropriate for use in fuel performance models until a more comprehensive set of experimental data become available. Irradiated thermal conductivity of FCM fuel pellets or compacts that contain TRISO particles inside a NITE-SiC matrix is expected to be consistent with this estimation since previous experimental observations did not show notable variation between the thermal conductivity of monolithic and particle-bearing NITE-SiC specimens in the as-fabricated [2] and irradiated [15] states. 

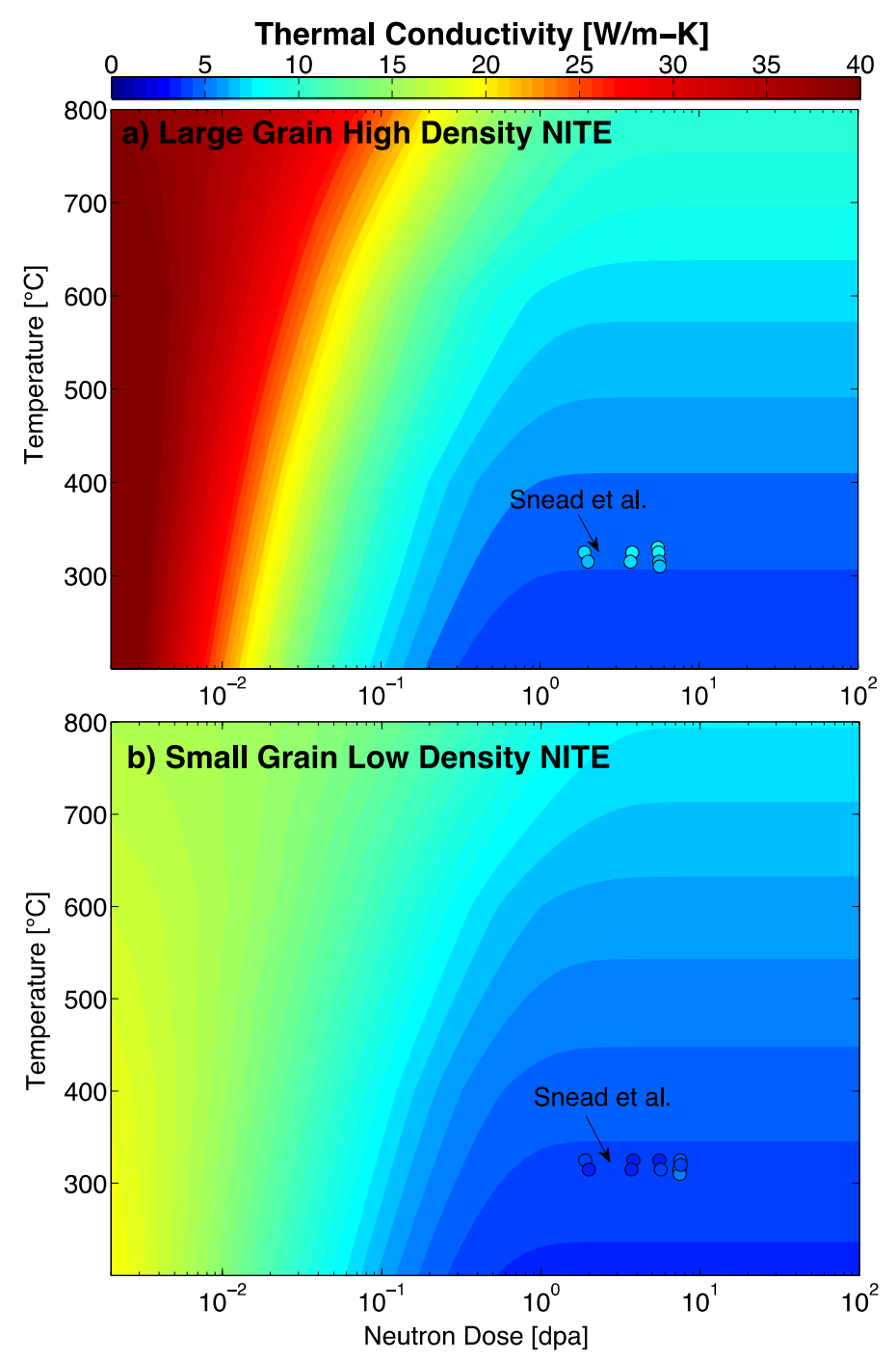

Fig. 8. Dose- and temperature-dependent estimation of thermal conductivity for two NITE-SiC variants presented along with limited experimental data from ref. [15].

\subsection{Statistical failure}

Monotonic equibiaxial testing was carried out on a number of unirradiated NITE-SiC variants produced from 40 and $80 \mathrm{~nm}$ powder feedstocks and machined from hot-pressed 6.5-cm-diameter plates. Weibull statistics were used to extract the failure probability shape and scale parameters from these tests and to determine statistical failure probability for this material as a function of stress. Weibull statistics imply that the probability of failure initiated from a bulk defect is given by

$$
P=1-\exp \left[\frac{-1}{V} \int_{V}\left(\frac{(\sigma}{\sigma_{0}}\right)^{m} d V\right]
$$


where $V$ is the characteristic volume, $m$ is the Weibull modulus (shape parameter), and $\sigma_{\circ}$ is the characteristic strength (scale parameter). The results of the equibiaxial flexural tests are shown in Fig. 9 and compared to CVD-SiC [32] as a reference. The scale and shape parameters are also summarized in Table 1. As shown in the figure, the failure probability distribution is consistent among the various NITE$\mathrm{SiC}$ specimens that were examined. The characteristic strength is slightly lower than that reported for CVD-SiC under similar experimental conditions. The batch of NITE-SiC produced with feedstock contaminated with YSZ (from milling media) exhibits a higher strength than the standard NITE and even CVD-SiC.

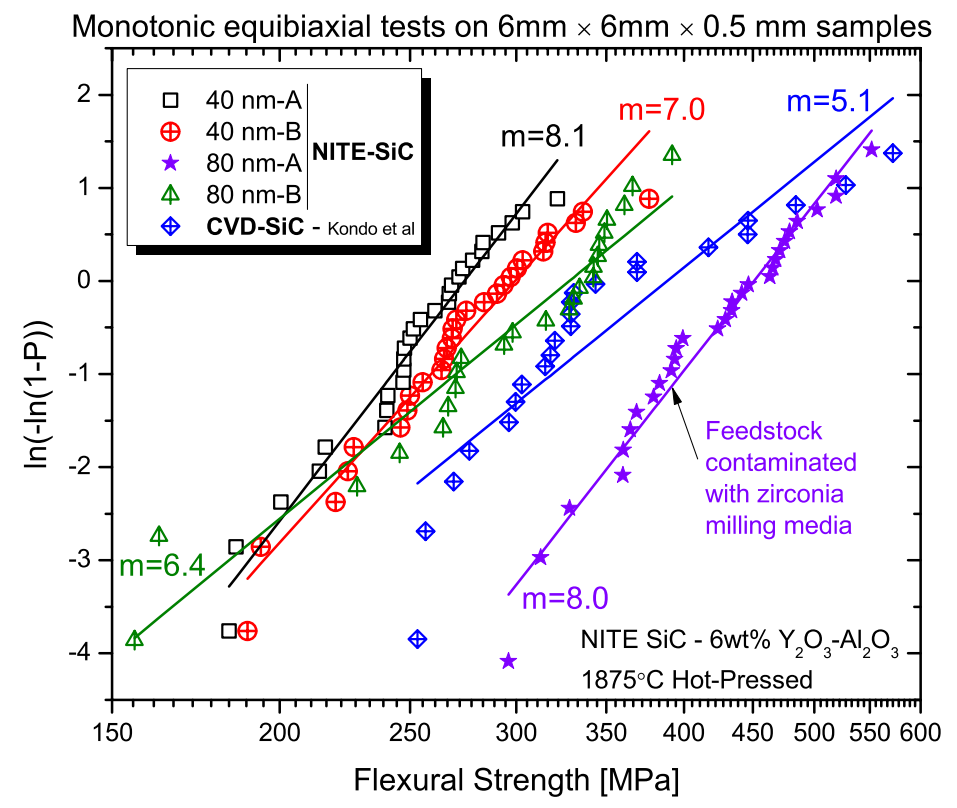

Figure 9. Weibull distribution of failure probability as a function of applied flexural stress on NITE-SiC specimens.

Table 1. Weibull shape and scale parameters for failure probability in monolithic NITE-SiC, $V=1.57$ $\mathrm{mm}^{3}$.

\begin{tabular}{ccc} 
SiC Variant & $\begin{array}{c}\text { Shape Parameter } \\
(\mathbf{m})\end{array}$ & $\begin{array}{c}\text { Scale Parameter } \\
\left(\boldsymbol{\sigma}_{\mathbf{0}}\right)[\mathbf{M P a}]\end{array}$ \\
\hline NITE-40nm-A & 8.1 & 259 \\
NITE-40nm-B & 7.0 & 280 \\
NITE-80nm-A & 8.0 & 426 \\
NITE-80nm-B & 6.4 & 304 \\
CVD & 5.1 & 355 \\
\hline
\end{tabular}

No comprehensive set of data on the effects of neutron irradiation on the strength of neutron irradiated NITE-SiC matrix is available. The most recent and pertinent work by Koyanagi et al. reports degradation in strength for neutron irradiated $\left(\sim 6 \mathrm{dpa}, \mathrm{T}>800^{\circ} \mathrm{C}\right)$ monolithic NITE-SiC where the characteristic 
strength was reduced by $\sim 40 \%$ [14]. In contrast, no significant effects of neutron irradiation on the tensile properties of NITE-SiC/SiC composites were observed in the same study.

\section{Processing Techniques Specific to FCM Fuel Form}

The basics and proof of concept demonstration of FCM fuel fabrication were discussed in ref. [11]. Optimization of the processing method and development of new techniques were necessary at the time to

produce intact, ideal, and reliable fuel form structures. This section discusses significant steps in this area; it also describes in detail number of new techniques that enable optimal fuel production.

\subsection{Particle overcoating}

High-temperature gas reactor fuel, consisting of TRISO particles embedded in a graphite matrix (in FCM fuel the graphite is replaced with $\mathrm{SiC}$ ), has enjoyed many decades of development and testing [33, 34]. The most recent developments and optimization in graphite matrix fuel form consolidation are summarized in ref. [35]. Particle overcoating, first demonstrated during fuel production for the Dragon reactor [36], has been a key element of fuel form consolidation to i) eliminate detrimental interparticle interactions during compacting and ii) enable accurate control over fuel loading. Although the consolidation process differs greatly between the graphite and the $\mathrm{SiC}$ matrices (e.g., carried out at $80{ }^{\circ} \mathrm{C}$ and $1875^{\circ} \mathrm{C}$, respectively), similar benefits can be realized during FCM fuel production if the particles are overcoated with NITE-SiC feedstock.

A setup similar to the one described in ref. [35] was assembled for particle overcoating with NITE-SiC feedstock. Briefly, it consists of a rotating stainless steel drum that hosts the particles while a slurry containing NITE-SiC is sprayed onto them. The spray apparatus consists of a syringe pump that feeds the slurry into a piezoelectric pump to produce a uniform mist. The drum is heated during the process to evaporate the solvent. The extent of heat input into the drum, drum rotation speed, slurry concentration, injection rate, and the piezoelectric pump operating frequency are all critical parameters in controlling the quality and characteristics of the overcoat layer. While in this case the nanopowder-bearing slurry is directly sprayed onto the particles, in the case of graphite matrix overcoating, a pure solvent is sprayed onto a mixture of particles and graphite-resin powders inside the drum.

The overcoating process described here is a scalable batch process, that results in simultaneous and uniform overcoating of a large number of fuel particles. In the end, powder-only agglomerates are smaller-diameter granules that can be sieved away. The results of this batch overcoating process are shown in Fig. 10. 

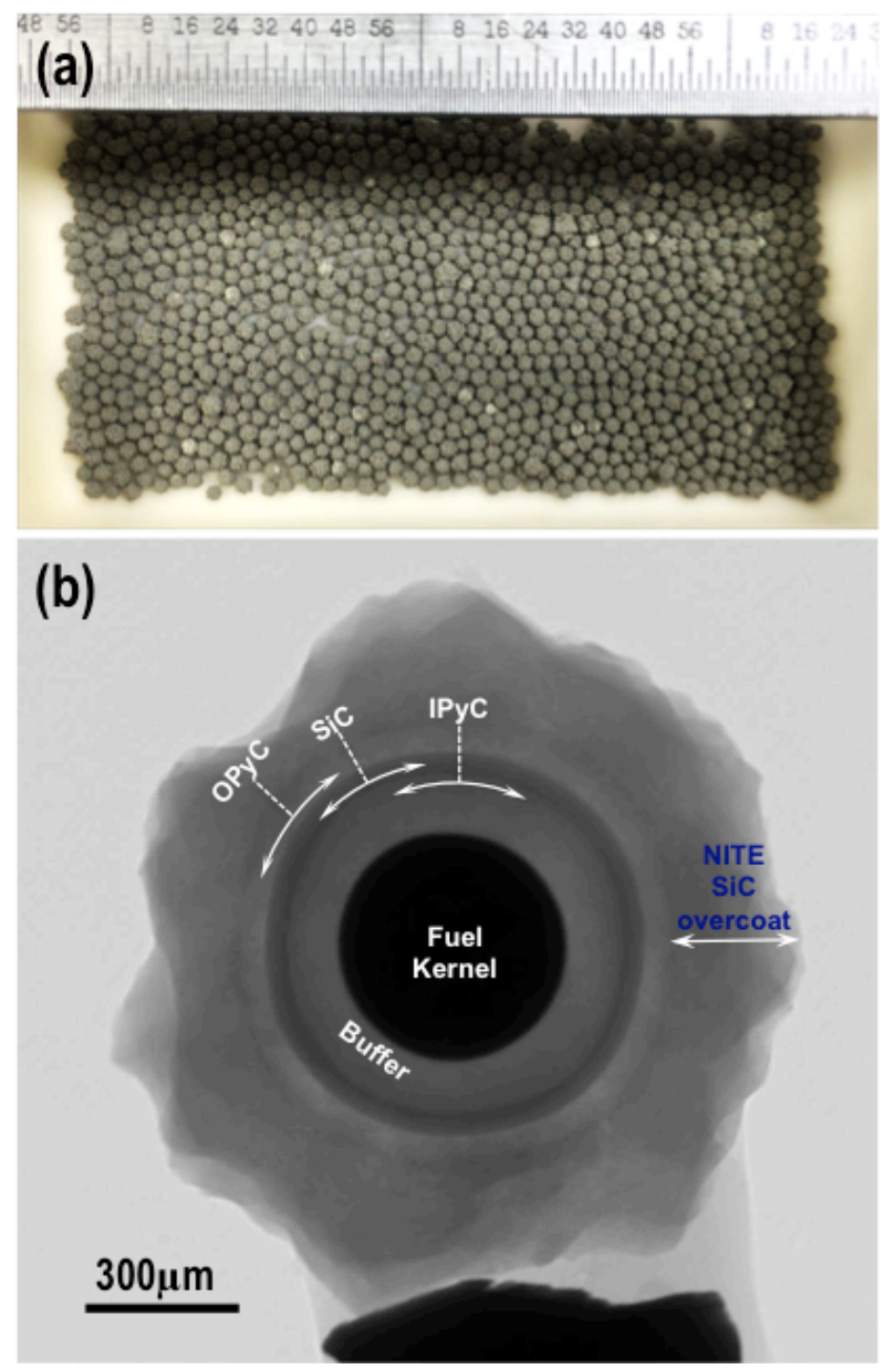

Fig. 10. (a) A batch of overcoated particles. (b) X-ray radiograph of a single overcoated particle.

\subsection{Pellet outer buffer incorporation}

To meet high geometric design tolerances, the surface of the FCM fuel pellet for light water reactor fuel application needs to undergo centerless grinding, much like the $\mathrm{UO}_{2}$ pellet used in today's fuel assemblies. The heterogeneous nature of the fuel complicates this step since any damage to particle coating layers as a result of this process needs to be avoided. Two approaches were examined in order to incorporate a particle-free outer buffer layer on the surface of these pellets that will act as a sacrificial layer during centerless grinding.

The first approach consists of production of a particle-free shell by cold pressing NITE feedstock and placing it around a particle-bearing green body. It is important that the cold pressing pressure for these two bodies is identical so that they experience similar densification during hot-pressing. Fig. 11 
demonstrates this approach, showing the composite structure along with flat particle-free disks placed on the top and bottom that underwent hot-pressing to produce the dense pellet.

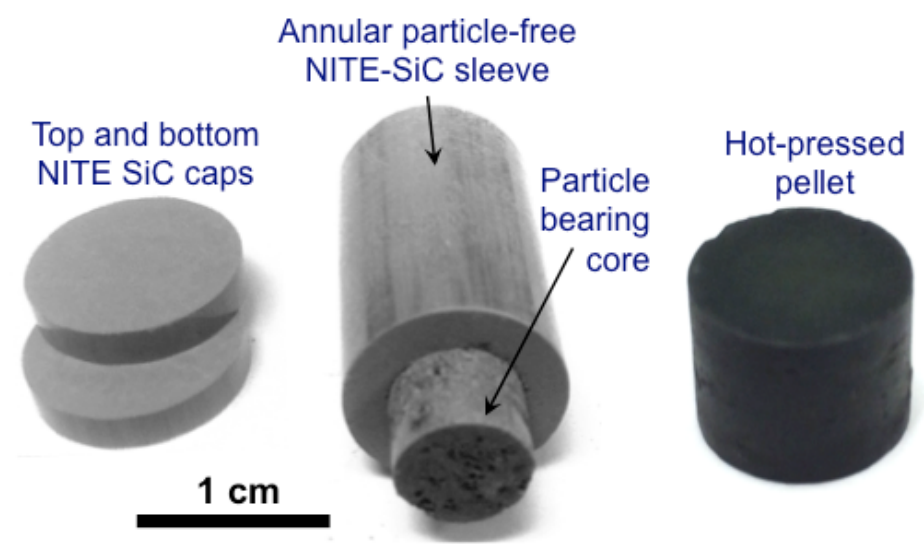

Fig. 11. Incorporation of a particle-free outer buffer on the FCM pellet using an annular NITE SiC shell.

The second approach uses a braided $\mathrm{SiC}$ fiber tube instead of a green shell to contain the particles away from the pellet surface. The fiber braids are impregnated with NITE-SiC slurry after they are placed around the particle-bearing core. The pellet ends are also covered with braided and impregnated SiC fiber disks. Figure 12(a) shows overcoated particles pressed into a green pellet and placed inside a braided Nicalon $\mathrm{SiC}$ fiber tube. This structure is then placed inside a graphite die and hot-pressed to produce a dense pellet, Fig 12(b). The SiC fiber braid effectively contains the particles away from the surface of the pellet. Fig. 12(b) shows two identical pellets that underwent centerless grinding to two different final diameters. A difference of less than $0.5 \mathrm{~mm}$ in radius between the two cases results in exposure of particles at the surface for the pellet with the smaller radius.

The ceramic grade Nicalon fiber consists of silicon carbide nano-crystallites embedded in the matrix of continuous silicon oxycarbide glass ( $\left.\mathrm{SiC}-25 \mathrm{wt} \% \mathrm{SiO}_{2}-10 \mathrm{wt} \% \mathrm{C}[24]\right)$. This microstructure, during heat treatment at $1875^{\circ} \mathrm{C}$ in inert atmosphere, naturally evolves so that the silicon carbide crystallites grow in size, $\mathrm{SiO}$ and $\mathrm{CO}_{\mathrm{x}}$ outgas, and the excess carbon may remain in pockets. In presence of the oxide additives in the surrounding matrix of the green NITE-SiC, silica and carbon join the sintering additive system, likely promoting the sintering. The resulting microstructure is similar to the NITE matrix consisting of a mixture of large and small crystalline $\mathrm{SiC}$ grains and oxide phases at the grain boundaries. In this manner, as shown in Figure 13, the original fiber braid is now well integrated with the rest of the matrix. 

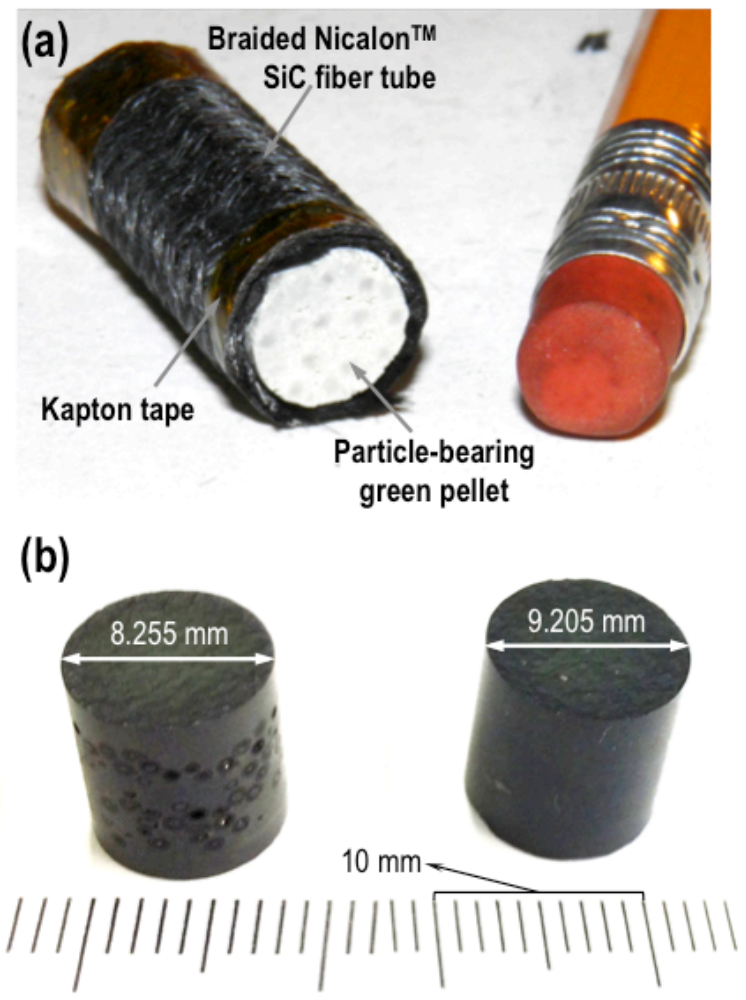

Fig. 12. (a) Green pellet inside SiC fiber braid before hot-pressing. (b) Hot-pressed FCM pellets after centerless grinding to different diameters, indicating that the particles are packed closely near the surface.

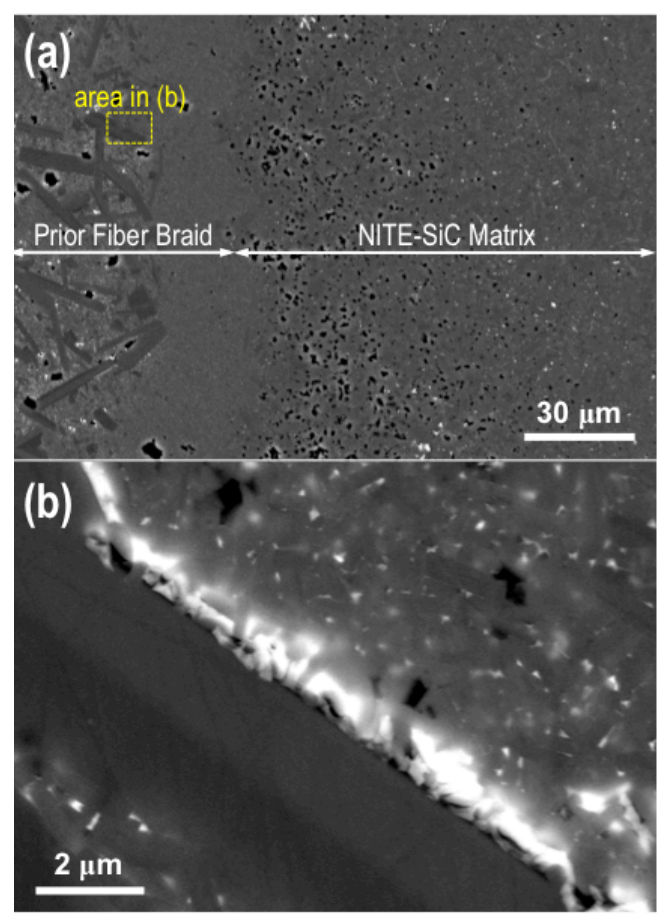

Fig. 13. (a) Interface between the prior Nicalon fiber braid and NITE-SiC matrix after hot-pressing and (b) detailed view of the microstructure of prior fiber braid impregnated with NITE-SiC slurry consisting of large and small crystalline $\mathrm{SiC}$ grains and oxide phase at the grain boundaries. 
$\mathrm{X}$-ray radiographs of pellets were produced to examine the distribution of particles in the matrix. Figure 14 is a top down view of pellets with outer buffer layers incorporated using the two methods described so far. The contrast in the image arises from the strong difference in attenuation coefficient between zirconium in the oxide kernel and the light elements (silicon and carbon). Therefore, the dark spots representing high $\mathrm{X}$-ray absorption are the oxide kernels; no contrast between the various coating layers and the NITE-SiC matrix can be attained using this setup. Figure 14(a, b) shows the pellet with a NITE$\mathrm{SiC}$ particle-free outer shell after hot-pressing. Although in most cases the particles remain within the core region, particles may occasionally drift outward, representing a concern during actual fuel production. Also, the outer shell in these cases is thick, and the pellet requires significant machining to remove most of it. In case of tubular SiC fiber braids, Fig. 14(c,d), a thin and effective outer layer is incorporated in the pellet that requires only minimal machining to achieve the smooth surface required for this application.
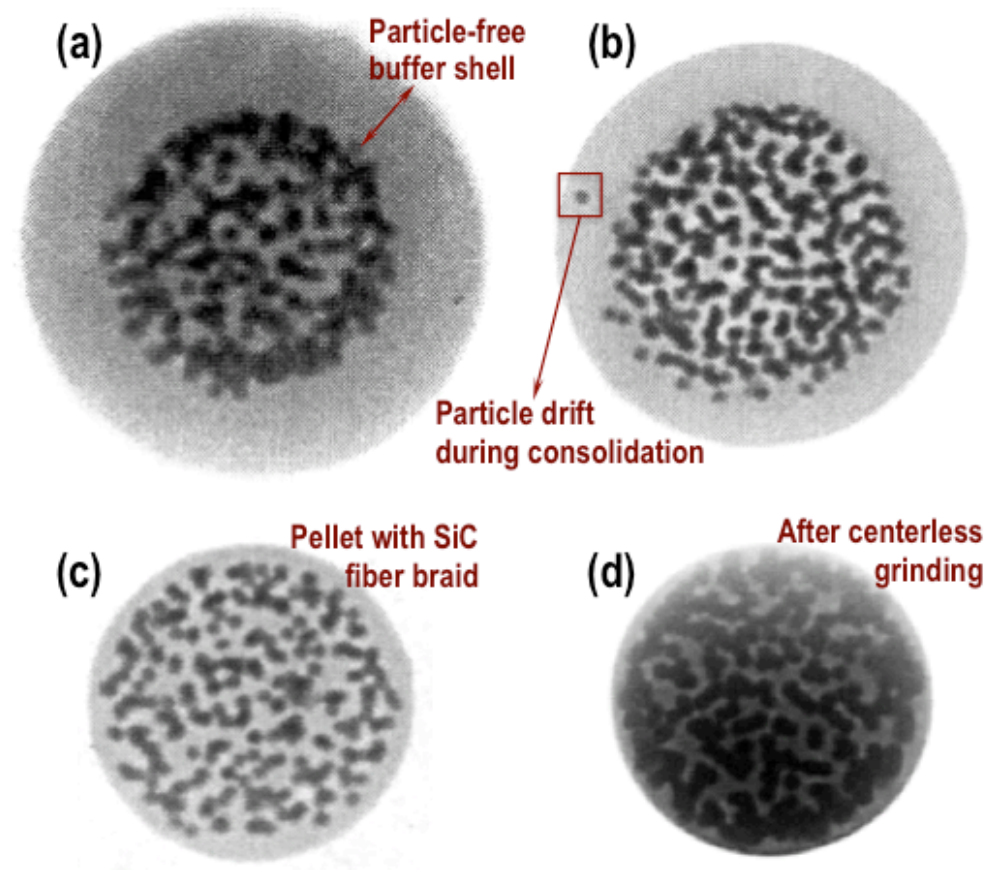

Fig. 14. Hot-pressed FCM pellets with (a, b) particle-free green outer shell placed around a particle-containing core during compacting and (c, d) with $\mathrm{SiC}$ fiber braid on the outside.

\subsection{Complex fuel structures}

The NITE process offers a high degree of flexibility to enable production of FCM fuel in a wide range of geometries beyond the pellet form discussed so far. Similar cold and hot-pressing processes could be used to produce plate shape structures and the graphite dies could be machined in such a manner to imprint channels or other topographic features on these plates. These structures could be joined subsequently, again, using the NITE process itself. A detailed discussion on SiC joining techniques, including NITE joints, and their irradiation stability is available elsewhere [37]. Figure 15 shows an example of such a 
structure where a NITE plate with surface grooves was bonded to a CVD-SiC plate. Therefore, it is feasible to envision coated fuel particles embedded inside NITE-SiC in integral structures with complex geometries that form the core for advanced nuclear reactor concepts.

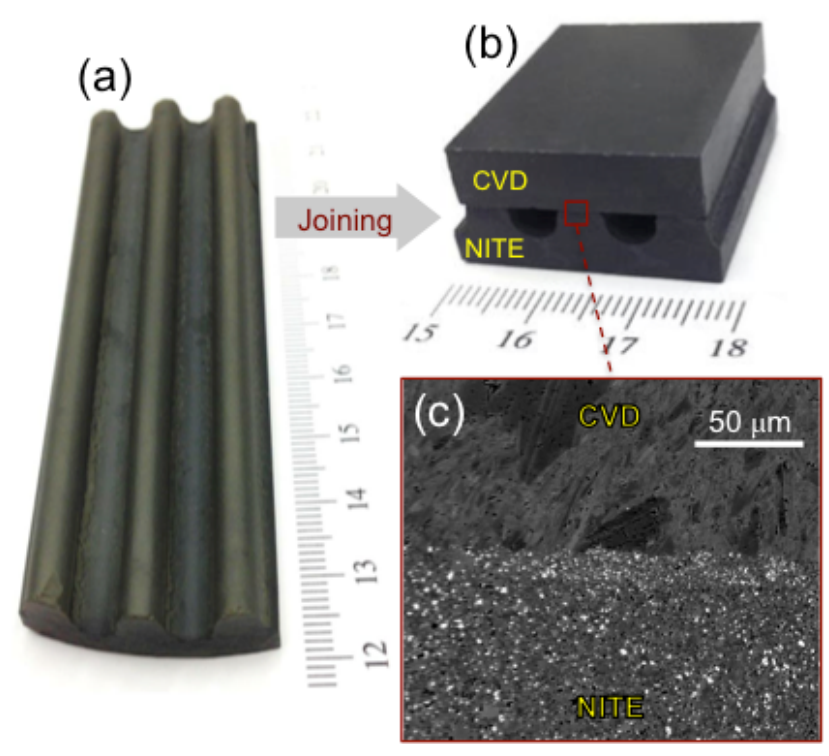

Fig. 15. a) Hot-pressed NITE SiC plate with surface grooves, b) grooved NITE plate bonded to CVD SiC via the NITE process to form a structure with embedded channels, c) backscattered electron image of the NITE SiC-CVD $\mathrm{SiC}$ joint.

\section{Summary}

This article describes the significant progress that has been accomplished in the development of the FCM fuel form. Initially, basic insights into the consolidation mechanism and the resulting nature of the NITE$\mathrm{SiC}$ matrix of the fuel form are provided. Coefficient of thermal expansion, thermal conductivity, and the fracture probability as a function of stress for the NITE-SiC matrix in the unirradiated state are reported and compared with CVD-SiC. An ad hoc and conservative formulation for estimation of thermal conductivity degradation as a result of neutron irradiation is also provided that complementary to the unirradiated properties should aid fuel performance modeling efforts. Finally, a number of specific processing techniques for production of optimal and reliable FCM fuel compacts are discussed.

\section{Acknowledgments}

B. Slone, S. Jurek, W. Porter, T. Geer, J. Su, M. Trammell, and J. Pryor contributed to the experimental investigations. T. Koyanagi provided useful comments on the manuscript. The work presented in this paper was supported by the Advanced Fuels Campaign of the Fuel Cycle R\&D program in the Office of Nuclear Energy, US Department of Energy. 


\section{References}

[1] L. L. Snead, K. A. Terrani, F. Venneri, Y. Kim, J. E. Tulenko, C. W. Forsberg, et al., "Fully Ceramic Microencapsulated Fuels: A Transformational Technology for Present and Next Generation ReactorsProperties and Fabrication of FCM Fuel," Transactions of the American Nuclear Society, vol. 104, 2011 2011.

[2] K. A. Terrani, L. L. Snead, and J. C. Gehin, "Microencapsulated fuel technology for commercial light water and advanced reactor application," Journal of Nuclear Materials, vol. 427, pp. 209-224, 2012.

[3] C. Gentry, I. Maldonado, A. Godfrey, K. Terrani, J. Gehin, and J. Powers, "A Neutronic Investigation of the Use of Fully Ceramic Microencapsulated Fuel for Pu/Np Burning in PWRs," Nuclear Technology, vol. 186, 2014.

[4] N. M. George, I. Maldonado, K. A. Terrani, A. Godfrey, J. Gehin, and J. Powers, "Neutronics Studies Of Uranium-Bearing Fully Ceramic Microencapsulated Fuel For Pressurized Water Reactors," Nuclear Technology, vol. in press, 2014.

[5] R. A. Shapiro, M. J. Vincenzi, and M. Fratoni, "Optimization Of Fully Ceramic Micro-Encapsulated Fuel Assembly For PWR," presented at the PHYSOR 2014, Kyoto, Japan, 2014.

[6] N. R. Brown, H. Ludewig, A. Aronson, G. Raitses, and M. Todosow, "Neutronic evaluation of a PWR with fully ceramic microencapsulated fuel. Part I: Lattice benchmarking, cycle length, and reactivity coefficients," Annals of Nuclear Energy, vol. 62, pp. 538-547, 2013.

[7] Y. Lee and N. Z. Cho, "Three-dimensional single-channel thermal analysis of fully ceramic microencapsulated fuel via two-temperature homogenized model," Annals of Nuclear Energy, vol. 71, pp. 254-271, 2014.

[8] C. W. Forsberg, K. A. Terrani, L. L. Snead, and Y. Katoh, "Fluoride-Salt-Cooled High-Temperature Reactor (FHR) with Silicon-Carbide-Matrix Coated-Particle Fuel," in American Nuclear Society Winter Meeting, San Diego, CA, 2012, pp. 907-910.

[9] M. Omori and H. Takei, "Pressureless sintering of SiC," Journal of the American Ceramic Society, vol. 65, pp. c92-c92, 1982.

[10] Y. Katoh, S. Dong, and A. Kohyama, "Thermo-mechanical properties and microstructure of silicon carbide composites fabricated by nano-infiltrated transient eutectoid process," Fusion engineering and design, vol. 61, pp. 723-731, 2002.

[11] K. A. Terrani, J. O. Kiggans, Y. Katoh, K. Shimoda, F. C. Montgomery, B. L. Armstrong, et al., "Fabrication and characterization of fully ceramic microencapsulated fuels," Journal of Nuclear Materials, vol. 426, pp. 268-276, 2012.

[12] J. J. Sha, T. Nozawa, J. S. Park, Y. Katoh, and A. Kohyama, "Effect of heat treatment on the tensile strength and creep resistance of advanced SiC fibers," Journal of Nuclear Materials, vol. 329-333, pp. 592596, 2004.

[13] N. Rohbeck and P. Xiao, "Effects of thermal treatment on the mechanical integrity of silicon carbide in HTR fuel up to $2200^{\circ} \mathrm{C}$," Journal of Nuclear Materials, vol. 451, pp. 168-178, 2014.

[14] T. Koyanagi, K. Ozawa, T. Hinoki, K. Shimoda, and Y. Katoh, "Effects of neutron irradiation on mechanical properties of silicon carbide composites fabricated by nano-infiltration and transient eutecticphase process," Journal of Nuclear Materials, vol. 448, pp. 478-486, 2014.

[15] L. L. Snead, K. A. Terrani, Y. Katoh, C. Silva, K. J. Leonard, and A. G. Perez-Bergquist, "Stability of SiCmatrix microencapsulated fuel constituents at relevant LWR conditions," Journal of Nuclear Materials, vol. 448, pp. 389-398, 2014.

[16] A. K. Kercher and J. D. Hunn, "Results from ORNL Characterization of ZrO2-500-AK2 - Surrogate TRISO Material, Rev 1," ORNL/TM-2005/540, 2005.

[17] J.-S. Park, A. Kohyama, T. Hinoki, K. Shimoda, and Y.-H. Park, "Efforts on large scale production of NITE-SiC/SiC composites," Journal of Nuclear Materials, vol. 367, pp. 719-724, 2007. 
[18] S. C. Singhal, "Thermodynamic analysis of the high-temperature stability of silicon nitride and silicon carbide," Ceramurgia International, vol. 2, pp. 123-130, 1976.

[19] H. Willems, M. Hendrix, R. Metselaar, and G. De With, "Thermodynamics of Alon I: Stability at lower temperatures," Journal of the European ceramic society, vol. 10, pp. 327-337, 1992.

[20] L. Dumitrescu and B. Sundman, "A thermodynamic reassessment of the Si-Al-O-N system," Journal of the European Ceramic Society, vol. 15, pp. 239-247, 1995.

[21] L. S. Sigl, "Thermal conductivity of liquid phase sintered silicon carbide," Journal of the European Ceramic Society vol. 23, pp. 1115-1122, 2003.

[22] J. Hales, R. Williamson, S. Novascone, D. Perez, B. Spencer, and G. Pastore, "Multidimensional multiphysics simulation of TRISO particle fuel," Journal of Nuclear Materials, vol. 443, pp. 531-543, 2013.

[23] L. L. Snead, T. Nozawa, Y. Katoh, T. S. Byun, S. Kondo, and D. A. Petti, "Handbook of SiC properties for fuel performance modeling," Journal of Nuclear Materials, vol. 371, pp. 329-377, 2007.

[24] Y. Katoh, K. Ozawa, C. Shih, T. Nozawa, R. J. Shinavski, A. Hasegawa, et al., "Continuous SiC fiber, CVI $\mathrm{SiC}$ matrix composites for nuclear applications: Properties and irradiation effects," Journal of Nuclear Materials, vol. 448, pp. 448-476, 2014.

[25] M. MUNRO, "Evaluated Material Properties for a Sintered alpha-Alumina," Journal of the American Ceramic Society, vol. 80, pp. 1919-1928, 1997.

[26] R. Wynne, J. L. Daneu, and T. Y. Fan, "Thermal coefficients of the expansion and refractive index in YAG," Applied optics, vol. 38, pp. 3282-3284, 1999.

[27] R. Aggarwal, D. Ripin, J. Ochoa, and T. Fan, "Measurement of thermo-optic properties of Y3A15O12, Lu3A15O12, YAIO3, LiYF4, LiLuF4, BaY2F8, KGd (WO4) 2, and KY (WO4) 2 laser crystals in the 80 300K temperature range," Journal of Applied Physics, vol. 98, p. 103514, 2005.

[28] R. J. Price, "Properties of silicon carbide for nuclear fuel particle coatings," Nuclear Technology, vol. 35, pp. 320-336, 1977.

[29] Y.-J. Lee, Y.-H. Park, and T. Hinoki, "Influence of Grain Size on Thermal Conductivity of SiC Ceramics," in IOP Conference Series: Materials Science and Engineering, 2011, p. 162014.

[30] C. Ronchi, M. Sheindlin, D. Staicu, and M. Kinoshita, "Effect of burn-up on the thermal conductivity of uranium dioxide up to $100.000 \mathrm{MWdt}^{-1}$, " Journal of Nuclear Materials, vol. 327, pp. 58-76, 2004.

[31] L. L. Snead, S. J. Zinkle, and D. P. White, "Thermal conductivity degradation of ceramic materials due to low temperature low dose neutron irradiation," Journal of Nuclear Materials, vol. 340, pp. 187-202, 2005.

[32] S. Kondo, Y. Katoh, and L. L. Snead, "Concentric ring on ring test for unirradiated and irradiated miniature SiC specimens," Journal of Nuclear Materials, vol. 417, pp. 406-410, 2011.

[33] H. Nickel, H. Nabielek, G. Pott, and A. Mehner, "Long time experience with the development of HTR fuel elements in Germany," Nuclear Engineering and Design, vol. 217, pp. 141-151, 2002.

[34] D. Petti, J. Maki, J. Hunn, P. Pappano, C. Barnes, J. Saurwein, et al., "The DOE advanced gas reactor fuel development and qualification program," JOM Journal of the Minerals, Metals and Materials Society, vol. 62, pp. 62-66, 2010.

[35] P. J. Pappano, T. D. Burchell, J. D. Hunn, and M. P. Trammell, "A novel approach to fabricating fuel compacts for the next generation nuclear plant (NGNP)," Journal of Nuclear Materials, vol. 381, pp. 2538, 2008.

[36] M. S. T. Price, J. R. G. Gough, and G. W. Horsley, "Fuel Element Fabrication For The Dragon Reactor Experiment," J. Brit. Nucl. Energy Soc., vol. 5, pp. 361-382, 1966.

[37] Y. Katoh, L. L. Snead, T. Cheng, C. Shih, W. D. Lewis, T. Koyanagi, et al., "Radiation-tolerant joining technologies for silicon carbide ceramics and composites," Journal of Nuclear Materials, vol. 448, pp. 497$511,2014$. 